\title{
A Real-Time Location System Design for Production Facilities Working under COVID-19 Pandemic Precautions
}

Sena Kır ( $\sim$ senas@sakarya.edu.tr)

Sakarya University: Sakarya Universitesi https://orcid.org/0000-0002-5615-8814

\section{Research Article}

Keywords: COVID-19, digital transformation, occupational health and safety, real-time location system, radio-frequency identification, ultra-wideband

Posted Date: February 22nd, 2022

DOI: https://doi.org/10.21203/rs.3.rs-873004/v1

License: (ㅇ (i) This work is licensed under a Creative Commons Attribution 4.0 International License.

Read Full License 


\section{Abstract}

By reason of the COVID-19 pandemic, essential digital transformations are taking place in many areas of business life. Although the most important one of these transformations is due to the widespread use of the remote working model, the production sector does not have the opportunity to switch to such a model completely. Therefore, it is inevitable to maintain social distance to prevent the spread of COVID-19 while working in production facilities. In this study, a real-time location system (RTLS) model is proposed to keep track of social distance in production facilities and to ensure occupational health safety (OHS) at the same time. Since the social distance rule is essential for every production facility, the most important feature of the proposed system is that it can easily be integrated into the standard personnel tracking system in almost every enterprise. Besides, the proposed RTLS is designed as an efficient system based on ultra-wideband and radio-frequency identification, which can operate as a closed-loop monitoring system within itself. An adequately installed RTLS can monitor the position of employees in real-time and provides to intervene in the situation instantly when necessary. In case of a violation of social distance or a situation against OHS, it can be prevented instantly by the proposed system. It is also a useful model in the management of emergencies.

\section{Introduction}

The COVID-19 pandemic has affected the whole world since December 2019, threatens human health and life not only with death rates but also its adverse effects on working life. Kudyba [1] emphasizes that the COVID-19 pandemic has brought a Y2K type disruption to many enterprises and that enterprises are accelerating their digital transformation processes as a remedy. Considering that the epidemic has caused digital technologies to accelerate [2], it would not be wrong to say that many different industry areas will be affected by the digital transformation process, and this effect will continue after the epidemic.

Enterprises have entered a compulsory digital transformation process while fulfilling consumer demands due to providing less interactive working environments and keeping the productivity of remote workers high [3]. In this context, Papadopoulos et al. [4] discussed that SMEs especially live in the digitalization process to secure enterprises continuity during the pandemic process. Similarly, Bartsch et al. [5] researched remote working service sector employees' work performance in the virtual environment in this digitalization process. Papagiannidis et al. [6] provide important insights into the potential of critical lessons to be learned from this first significant pandemic in the digital age and how enterprises can be better prepared for future pandemics collaboration between diversified stakeholders to minimize enterprise's risks. Within the scope of social distancing precautions, enterprises should establish the right balance of traditional and remote models while updating their business models in terms of working remotely, increasing worldwide [7].

The digital transformation processes considered within the scope of the COVID-19 pandemic in the literature cover business activities outside the production area. This study aims to contribute to the 
literature by addressing the digital transformation processes in production areas during the pandemic. Because researches show that many production activities have come to a halt due to the spread of COVID-19 [8]. The motivation of this study is that enterprises that have to produce in a closed area within the scope of COVID-19 precautions have to maintain the social distance during their production activities. The researches and precautions are taken to prevent the spread of COVID-19 at workplaces in various areas around the business world draw attention [9, 10]. Rácz-Szabó et al. [11] stated in their studies that real-time location system (RTLS) based systems could be useful within the scope of the COVID-19 pandemic. Ho et al. [12], similarly to this study, investigated the interaction between the patients hospitalized in the COVID-19 service and the medical staff by integrating an RTLS into their electronic medical record system.

As a result of the researches, it has been determined that a mechanism is needed to ensure that the staff complies with the social distance rule while working. Based on this, a cost-efficient system has been designed to maintain social distance and be useful in the field of occupational health and safety (OHS) and can be implemented in the personnel tracking system of almost every enterprise. The proposed system is based on a kind of RTLS and enables collecting and managing all information regarding the production area's activities. There are various studies in the literature before the COVID-19 pandemic that proposed kinds of RTLSs for OHS in manufacturing, especially the construction industry. For example, Dong et al. [13] proposed an RTLS to determine and track the misused or non-used personal protective equipment. Li et al. [14] and Soltanmohammadlou et al. [15] conducted extensive research on RTLSs developed specifically for OHS in the construction industry. However, none of these and similar studies include the OHS precautions that come into our lives with COVID-19. Therefore, the RTLS proposed in this study will contribute to the literature, especially in the manufacturing industry.

The remaining sections of this paper are organized as follows. Section 2 presents the background of this study in terms of working under COVID-19 precautions in a production facility. Section 3 explains RTLS and other technologies used with RTLSs and details the proposed RTLS. Section 4 describes the results obtained when the system works correctly and effectively. Finally, the usefulness, advantages, and limitations of the system are discussed in Sect. 5.

\section{Background}

The enterprises update their working policies in production facilities parallel to COVID-19 pandemic precautions. Policies for presence in public areas, personnel vehicle usage rules, number of employees per shift, etc., are rearranged according to the determined maintaining social distance precaution. In particular, precautions are taken to reduce the number of people per unit area to ensure social distance. The number of people that can be taken to indoor spaces at the same time is determined according to the available spaces. The number of personnel vehicles and the number of people in the vehicles is arranged, maintaining social distance. The number of personnel per shift is regulated according to maintaining social distance, and if necessary, increases can be made in the number of shifts. Physical arrangements 
can be made in the dining hall and common areas that will not allow people to sit side-by-side and ensure that they sit at a distance.

Especially for individuals who live in a society with strong social relations, despite all these precautions, it can be challenging to prevent people from coming together and make them maintaining social distance. Besides, in the case of COVID-19 incidence in the production facilities, the other workmates with whom the infected employee are in contact cannot be determined precisely. There is a risk that the infected employee may not remember exactly who they were in contact with or that they would not share their names because they do not want their workmates to be quarantined. In other words, even $100 \%$ contact tracing (filiation) is not enough to solve this problem. In case of an incident, enterprises can quarantine all employees who may contact the infected employee, interrupt production at the production facility where the incident occurs, disinfect the facility, and restart production. This situation can cause severe production losses.

Considering the pre-pandemic literature, there are different system recommendations based on RTLS that provide automatic personnel tracking in the field of $\mathrm{OHS}[16,17,18,19]$. However, these systems need to be updated by the COVID-19 pandemic rules. It is difficult to predict whether this situation is possible and its cost. The solution that enterprises need a system that they can integrate into existing personnel tracking systems at a low cost. Commonly, there is a card tracking system that controls the entry and exit of the enterprises' personnel. The RTLS based system proposed in this study is a system that can be integrated into a simple personnel tracking system and has a low additional investment cost.

The solution sought is to block the contact instantly, without leaving it to the preference of individuals. As a result of research on this, it is suggested to implement an RTLS that can be integrated into almost every enterprise's personnel tracking system.

\section{Materials And Methods}

An RTLS has been proposed to ensure OHS in production facilities, especially to maintain social distance while working within the scope of COVID-19 precautions. In the literature, RTLSs appear with different technologies. In this study, an ultra-wideband (UWB) and radio-frequency identification (RFID)-based RTLS is proposed. The characteristics, components, system architecture, and operating mechanism of the proposed system are detailed in this section.

\subsection{RTLSs and Other Technologies Used Together}

RTLS is a wireless technology solution that can be applied in various fields and is widely used worldwide to increase business efficiency and quality. Many technologies are used, such as wireless fidelity (Wi-Fi) [20], RFID [21], infrared [22], UWB [23], ZigBee [24], BLE (bluetooth low energy) [25] to determine the realtime location. Besides, studies using these technologies together are also available in the literature. For example, UWB RFID-based [26], RFID Wi-Fi-based [27], ZigBee and RFID-based [17], etc., systems were presented to literature before. 
In the industry, RFID technology is frequently used for tracking purposes. The RTLS technologies classification evaluated for the problem's solution in this study is given in Fig. 1 [11, 28]. Among these technologies, a UWB RFID-based system has been designed in this paper because it is cost-effective, efficient, and easier to integrate into the system.

RFID and RTLS are different from each other. RFID is to identify an object or person tagged over a wireless communication network. It can be used for defining, managing, and positioning a tagged object [29]. RTLS offers the ability to detect and track the real-time location of an object or person carrying an RFID tag over wireless networks. Real-time systems can report an object's absolute position based on a small number of variables such as expected current and/or next location, previous locations, and available technology. In many cases, using RFID, RTLS and barcoding together can be an ideal solution [30].

RFID is a wireless communication technology used to identify objects using radio waves. RFID systems consist of an object carrying a tag equipped with a microprocessor, an antenna, a reader, a host/server, and software. Each tag has its unique number. For any object to be identified, the reader sends radio frequencies, and then the recognition process takes place according to the particular unique number coming from the tag. The transfer of information and energy between tag and reader is achieved without any contact. This communication can be bidirectional. Tags are separated as active or passive depending on whether the power source is connected or not. In this paper, active UWB frequency tags were preferred for the proposed RTLS. These tags operate in the $3.1-10.6 \mathrm{GHz}$ frequency range. Rather than sending a very strong signal from a particular frequency, a low power signal can be sent over a wide band with UWB. Besides, the transmission of the signal is healthier. It can be read up to 200 meters. It is not affected by metal, liquid environments, and environmental conditions in precise readings. Thus, choosing UWB frequency RFID tags will be the most appropriate option, especially for personnel cards.

The RFID systems, which are widely used in RTLS today, can communicate wirelessly between readers and carriers without directly seeing each other, making it easier to use the system in the building. In this respect, RTLSs are defined as location tracking systems that enable determining the exact location of objects or personnel within the facility using wireless technologies. Enterprises using RTLS suffer from the lack of awareness of their employees, despite the restructuring of all business processes and simplifying high-level integrations in server applications. Due to the easy integration with server applications, uniform barcode and passive RFID tags still adhere.

In terms of RTLS market technology-based segregation, wireless network-based RTLSs bring undisputed advantages compared to proprietary technologies such as UWB and ZigBee due to the use of the existing wireless network Wi-Fi infrastructure. Wireless networking and active RFID-based solutions are promising for the market. Also, emerging technologies such as UWB and ZigBee, due to the high accuracy and precision they offer, are expected to surpass wireless networks and other traditional technologies, creating very fast-growing and developing markets.

\subsection{The Proposed UWB and RFID-Based RTLS}


In this section, what kind of real-time monitoring system the industry needs to ensure social distance and $\mathrm{OHS}$ in production areas is discussed. The real-time tracking system components, which are proposed considering the industry's needs, and its working mechanism and architecture, are presented.

\subsubsection{The Proposed RTLS Components}

The elements of the proposed RTLS are personnel ID cards, local and global remote readers in the production facility and social area, RFID enabled device, database, remote and closed-loop monitoring systems. The specifications of the system components are given below.

Personnel ID Cards: Each staff holds their Personnel ID Cards located on each staff creates an area around him/her with UWB-based RFID technology. The active UWB frequency tags were preferred due to the advantages detailed in Sect. 3.1. By the created area, each staff creates their social distance with their Personnel ID Card. The cards also have a vibration feature to alert when the social distance is violated and when a dangerous situation occurs in terms of occupational health and safety. When a social distance violation and a dangerous situation occurs, date, time, location, and ID information are stored on the card.

Local Remote Reader (LRR): The information on the personnel ID cards entering the influence area is wirelessly transferred to the software through these readers. For the system to work effectively and efficiently, the LRRs must be placed in the production area in the optimum number and manner.

Global Remote Reader: The global remote reader is the manager of the LRRs, who classifies the information received from the local zone readers and transmits them to the closed-loop monitoring system and software.

UWB RFID Enabled Device: These devices work as the personnel ID cards but are located on the forklifts.

Database: The system can use the existing database; it does not need a private or external database.

Remote Monitoring Systems: Since all data are kept in the database, they can be monitored remotely if desired. Although new technology remote monitoring systems performance is adequate, closed circuit monitoring of the production area is also recommended.

Closed-Loop Monitoring System: Since the data coming from the production area must be followed instantly, it is essential for detecting emergencies and instant intervention.

The data flow between all system components occurs at five levels in total. Figure 2 shows these levels.

\subsubsection{System Architecture and Working Mechanism}

Generally, enterprises have existing personnel tracking systems. The proposed RTLS will require several devices that can be easily implemented into these personnel tracking systems. By these devices, UWB 
RFID-enabled personnel cards warn employees by vibration when they come to a distance where they can perceive each other (when the social distance is violated). Simultaneously, the information about this closeness (ID information of the other card, time, and locations) is recorded in the cards. When the employee enters the influence area of LRR, this information is transmitted through the LRR to the global remote reader and then to the closed-loop monitoring environment. If necessary, instant intervention to the event is possible from the closed-loop monitoring environment. The data flow of this sub-system is shown in Fig. 3.

In another situation, the same system is activated in case a forklift, which has a UWB RFID-enabled device on it, or an employee comes dangerously close to another identical forklift. The device on the forklift sends the information of dangerous closeness to the nearest LRR. The LRR sends this information to the global remote reader, from where it will be transferred to the closed-loop monitoring environment. From the closed-loop monitoring environment, the forklift can be automatically stopped remotely. The data flow of this sub-system is shown in Fig. 4. Figure 4a shows the data flow from the forklift, and Fig. $4 \mathrm{~b}$ shows the data flow from the personnel ID card.

The most important thing here is that the forklift is located under the influence area of an LRR. Otherwise, the system cannot send instant alerts. Therefore, it is essential for the system efficiency to accurately determine the number and locations of LRRs in the production and social areas.

In case of an occupational accident, if the employee stays still for a while, the data is transferred to the closed-loop monitoring environment with the same system as a warning. The system facilitates the follow-up of the employees at the emergency assembly point in a disaster or extraordinary situation. Namely, the presence of the employees at the meeting point can be monitored instantly by the ID cards, and the absent employee can be detected, and instant intervention can be provided. The system architecture of the proposed RTLS is as shown in Fig. 5.

The RTLS architecture given in Fig. 5, social distance control for OHS in the COVID-19 pandemic, prevention of employee and forklift accidents, and remote organization processes in emergencies are entirely digitalized. All data obtained from the system can be stored, if desired, the enterprise can be processed for use in different processes and can be monitored instantly from outside the production area.

\subsubsection{Determining the Number of Local Remote Reader}

The number and location of LRR are essential for the efficiency of the system. If the situations that require instant intervention occur outside the influence area of the LRR, the emergency action will not be able to take place, as instant information will not reach the relevant location. However, the installation cost of the system which LRR placement to cover the whole area will be high. Huang et al. [26] presented an LRR placement model in a way that the influence areas overlap and cover the whole area. In this study, two different LRR placement policies have been proposed. One of them is to place LRRs in a way that 
leaves no blind zone likewise Huang et al. [26]. The other policy is to place the LRRs so that their influence areas do not overlap.

Policy \# 1: Starting from one corner of the area where the system will be installed, they are placed in such a way that no area remains outside the influence area of the LRRs. The influence areas of the LRRs intersect; there are no gaps or blind zone in between. Figure 6 shows the image of this placement policy.

Policy \# 2: Starting from the one corner of the area where the system will be installed, the influence areas of LRRs are placed tangentially around each other. The influence areas of the LRRs do not intersect; there are gaps or blind zone in between. There is a little blind zone as possible in areas close to walls, too. Figure 7 shows the image of this placement policy.

According to both policies, the approximate number of LRRs to be used in the placement are calculated as in Table 1, which is under the conditions $x y>\pi r 2$ and $x \geq y$ must be met. Also, depending on the number of required LRR, the approximate blind zone that can occur in such a situation can be calculated as in Table 1 with $\varepsilon$ denotes a small number (margin of error) considering the blind zone formula by Bayrakdar [31].

Table 1

Determining the approximate number of required LRR and blind zone according different policies

\begin{tabular}{|c|c|c|c|}
\hline & \# of Required LRR & Blind Zone & \\
\hline Policy \#1 & $\left\lceil\frac{\mathrm{x}}{2 \mathrm{r}}\right\rceil\left(\left\lceil\frac{\mathrm{y}}{2 \mathrm{r}}\right\rceil+1\right)$ & No blind zone & \\
\hline Policy \#2 & $\left\lceil\frac{\mathrm{x}}{2 \mathrm{r}}\right\rceil\left\lceil\frac{\mathrm{y}}{2 \mathrm{r}}\right\rceil$ & $\left\lceil\frac{\mathrm{x}}{2 \mathrm{r}}\right\rceil\left\lceil\frac{\mathrm{y}}{2 \mathrm{r}}\right\rceil\left(\begin{array}{c}\mathrm{r}^{2}(2 \sqrt{3}-\Pi) \\
\overline{2}\end{array}\right.$ & $-\square$ \\
\hline
\end{tabular}

Considering the current layout of the production facility, only one or both of these policies can be used in the same area. Policy \# 1 is suggested in an area where mobility is high, and policy \# 2 is suggested in an area where mobility is low.

\section{Results}

The proposed RTLS warns the personnel who violate the social distance precaution by the vibrating personnel ID card they carry. Personnel who get dangerously close to a forklift will also be warned in the same way, by the closed-loop monitoring system, the forklift will be able to stop remotely when necessary. Likewise, when two forklifts get dangerously close to each other, they can be stopped remotely. In emergencies, staff who are absent at the emergency meeting point can be identified and found easily, taking into account the information of the last location. For the proposed system to provide 
the mentioned service in the most accurate way with the lowest installation cost, the number of LRRs and their locations should be determined appropriately.

\subsection{Implications for Occupational Health Practice}

The equations for calculating the number of LRR are given in Sect. 3.2.3 for the proposed RTLS to work effectively and efficiently. To make the most appropriate RTLS installation in a representative production facility in Fig. 8, these equations were considered.

According to a representative production facility layout given in Fig. 8, the approximate LRR requirements and the approximate blind zone that may occur accordingly were calculated as in Table 2 considering Equations 1-7 where the influence area (2r) of an LRR is $6000 \mathrm{~cm}$. Since thick walls affect the signal strength, it is recommended to consider each area surrounded by thick walls separately.

Table 2

Approximate LRR requirement and blind areas that may occur according to a representative production facility layout

\begin{tabular}{|c|c|c|c|c|c|c|}
\hline \multirow[t]{2}{*}{ Location } & \multirow[t]{2}{*}{$x(\mathrm{~cm})$} & \multirow{2}{*}{$\begin{array}{l}y \\
(\mathrm{~cm})\end{array}$} & \multicolumn{2}{|c|}{ Policy \#1 } & \multicolumn{2}{|c|}{ Policy \#2 } \\
\hline & & & $\begin{array}{l}\text { \# of } \\
\text { LRR }\end{array}$ & $\begin{array}{l}\text { Blind Zone } \\
\left(\mathrm{cm}^{2}\right)\end{array}$ & $\begin{array}{l}\text { \# of } \\
\text { LRR }\end{array}$ & $\begin{array}{l}\text { Blind Zone } \\
\left(\mathrm{cm}^{2}\right)\end{array}$ \\
\hline Production Area & 10200 & 6880 & 6 & - & 4 & $5,790,648.42$ \\
\hline Warehouse & 6880 & 5800 & 4 & - & 2 & $2,888,067.76$ \\
\hline $\begin{array}{l}\text { Dining Hall \& Social } \\
\text { Area }\end{array}$ & 8000 & 4562 & 4 & - & 2 & $2,888,067.76$ \\
\hline Changing Room & 3000 & 1138 & 2 & - & 1 & $1,436,777.43$ \\
\hline Kitchen & 5000 & 1138 & 2 & - & 1 & $1,436,777.43$ \\
\hline
\end{tabular}

The values given in Table 2 have been calculated to give an idea before installation of the proposed RTLS, and it is possible to obtain different values in different LRR placement policies. For example, policy \#1 can be chosen for the production area because of the high mobility and 6 LRRs are placed. Conversely, policy \#2 can be chosen for the warehouse because of the low mobility and 2 LRRs are placed. Namely, if the blind zone is technically risky, policy \#1 should be preferred. In large areas, both policies can be preferred.

Also, system installation in the administrative building is not recommended. Because the staff working here can work home office during the COVID-19 pandemic.

\section{Discussion}


After determining that the Sars-CoV-2 virus was spread through droplets, profound changes had to be made in the social rules of all life. It has become necessary to wear a mask without exception in social situations, and the whole world has met a new concept called social distance. Social distance means a physical distance between human relations in all areas of life, although its size varies from country to country. People who moved away from each other physically with the increase of physical distance had to connect with digital technologies. This situation has led to the acceleration of digital transformation in many life areas, especially in business and education.

Remote working has become widespread in industries, and enterprises have to face advantages and disadvantages. The spread of the virus has been tried to be kept under control with new rules in production areas that cannot be worked remotely. The most important of these rules is maintaining social distance. New regulations were made in the physical conditions of production areas to maintain social distance, the staff was trained, new working procedures were developed, and the staff was monitored continuously according to the symptoms of people infected with the virus. Despite all the precautions taken at manufacturing facilities, it has not been possible to prevent the spread of COVID-19.

Consequently, some enterprises had to stop production for days, and in some countries even had to pay fines to the state. Because it is challenging to predict whether people in production areas comply with these rules without an automated system. In this paper, an RTLS is proposed to make all the precautions taken to prevent the spread of COVID-19 in production facilities more meaningful. Maintaining social distance should not be left to the initiative of individuals, it should be tracked automatically. Besides, with the proposed RTLS, it is possible to detect other dangerous approaches and prevent some work accidents too.

The limitation of the proposed system is that the RTLS is designed to work in closed spaces. By integrating different technologies into this system, it is possible to ensure both social distance and OHS in open areas.

\section{Declarations}

\section{Conflicts of Interest}

The author declares no conflict of interest

\section{Funding}

No funding is provided for the preparation of the manuscript

\section{References}

[1] Kudyba, S. (2020). COVID-19 and the acceleration of digital transformation and the future of work. Information Systems Management, 37(4), 284-287. 
https://doi.org/10.1080/10580530.2020.1818903

[2] Soto-Acosta, P. (2020). COVID-19 pandemic: shifting digital transformation to a high-speed gear. Information Systems Management, 37(4), 260-266.

https://doi.org/10.1080/10580530.2020.1814461

[3] Dwivedi, Y. K, Hughes, D. L, Coombs, C., Constantiou, I., Duan, Y., Edwards, J.S., Gupta, B., Lal, B., Misra, S., Prashant, P., Ramam, R., Rana, N.P., Sharma, S.K., \& Upadhyay, N. (2020). Impact of COVID-19 pandemic on information management research and practice: Transforming education, work and life. International Journal Information Management,55, 102211.

https://doi.org/10.1016/j.ijinfomgt.2020.102211

[4] Papadopoulos, T., Baltas, K. N., \& Balta, M. E. (2020). The use of digital technologies by small and medium enterprises during COVID-19: implications for theory and practice. International Journal Information Management, 55,102192. https://doi.org/10.1016/j.jijinfomgt.2020.102192

[5] Bartsch, S., Weber, E., Büttgen, M., \& Huber, A. (2020). Leadership matters in crisis-induced digital transformation: how to lead service employees effectively during the COVID-19 pandemic. Journal of Service Management, 32(1), 71-85. https://doi.org/10.1108/JOSM-05-2020-0160

[6] Papagiannidis, S., Harris, J., \& Morton, D. (2020). WHO led the digital transformation of your company? a reflection of IT related challenges during the pandemic. International Journal Information Management, 55, 102166. https://doi.org/10.1016/j.jinfomgt.2020.102166

[7] Nagel, L. (2020). The influence of the COVID-19 pandemic on the digital transformation of work. International Journal of Sociology and Social Policy, 40(9/10), 861-875. https://doi.org/10.1108/IJSSP07-2020-0323

[8] Araya, F. (2021). Modeling the spread of COVID-19 on construction workers: An agent-based approach. Safety Science,133, 105022. https://doi.org/10.1016/j.ssci.2020.105022

[9] Kang, S. K. (2020). COVID-19 and Middle East respiratory syndrome infections in health-care workers in Korea. Safety and Health at Work,11(2), 125-126. https://doi.org/10.1016/j.shaw.2020.04.007

[10] Kim, E. A. (2020). Social distancing and public health guidelines at workplaces in Korea: responses to coronavirus disease-19. Safety and Health at Work,11(3), 275-283.

https://doi.org/10.1016/j.shaw.2020.07.006

[11] Rácz-Szabó, A., Ruppert, T., Bántay, L., Löcklin, A., Jakab, L., \& Abonyi, J. (2020). Real-time locating system in production management. Sensor, 20(23), 6766. https://doi.org/10.3390/s20236766

[12] Ho, H. J., Zhang, Z. X., Huang, Z., Aung, A.H., Lim, W.Y., \& Chow, A. (2020). Use of a real-time locating system for contact tracing of health care workers during the COVID-19 pandemic at an infectious disease center in Singapore: validation study. Journal of Medical Internet Research, 22, e19437. 
[13] Dong, S., Li, H., \& Yin, Q. (2018). Building information modeling in combination with real time location systems and sensors for safety performance enhancement. Safety Science, 102, 226-237. https://doi.org/10.1016/j.ssci.2017.10.011

[14] Li, H., Chan, G., Wong, J. K. W., \& Skitmore, M. (2016). Real-time locating systems applications in construction. Automation in Construction. 63, 37-47. https://doi.org/10.1016/j.autcon.2015.12.001

[15] Soltanmohammadlou, N., Sadeghi, S., Hon, C. K., \& Mokhtarpour-Khanghah, F. (2019). Real-time locating systems and safety in construction sites: A literature review. Safety Science, 117, 229-242. https://doi.org/10.1016/j.ssci.2019.04.025

[16] Longkang, W., Baisheng, N., Ruming, Z., Shengrui, Z., \& Hailong, L. (2011). ZigBee-based positioning system for coal miners. Procedia Engineering, 26, 2406-2414.

https://doi.org/10.1016/j.proeng.2011.11.2452

[17] Barro-Torres, S., Fernández-Caramés, T. M., Pérez-Iglesias, H. J., \& Escudero, C.J. (2012). Real-time personal protective equipment monitoring system. Computer Communications, 36, 42-50. https://doi.org/10.1016/j.comcom.2012.01.005

[18] Lee, H. S., Lee, K. P., Park, M., Baek, Y., \& Lee, S. (2012). RFID-based real-time locating system for construction safety management. Journal of Computing in Civil Engineering, 26, 366-377. https://doi.org/10.1061/(ASCE)CP.1943-5487.0000144

[19] Ulku, A.(2017). The next generation in personneln/people tracking: Active RFID technology has allowed for enhanced security and safety. IEEE Consumer Electronics Magazine, 6, 122-124. https://doi.org/10.1109/MCE.2017.2714418

[20] Urrea, W. A., \& Ariza, H. M. (2017). Real time location system (RTLS) focused on the optimization of efficiency for hospital center assistance. International Journal of Applied Engineering Research, 12(15), 5248-5253.

[21] Kirch, M., Poenicke, O., \& Richter, K. (2017). RFID in logistics and production-applications, research and visions for smart logistics zones. Procedia Eng, 178, 526-533.

https://doi.org/10.1016/j.proeng.2017.01.101

[22] Jeong, I. C., Bychkov, D., Hiser, S., Kreif, J.D., Klein, L.M., Hoyer, E.H., \& Searson, P.C. (2017). Using a real-time location system for assessment of patient ambulation in a hospital setting. Archives of Physical Medicine and Rehabilitation,98(7), 1366-1373. https://doi.org/10.1016/j.apmr.2017.02.006

[23] Ruppert, T., \& Abonyi. J. (2018). Software sensor for activity-time monitoring and fault detection in production lines. Sensors, 18(7), 2346. https://doi.org/10.3390/s18072346

[24] Huircán, J. I., Muñoz, C., Young, H., Von Dossow, L., Bustos, J., Vivallo, G., \& Toneatti, M. (2010). ZigBee-based wireless sensor network localization for cattle monitoring in grazing fields. Computers and 
[25] Astafiev, A., Zhiznyakov, A., \& Privezentsev, D. (2019). Development of Indoor Positioning Algorithm Based on Bluetooth Low Energy beacons for Building RTLS-Systems. In Proceedings of the International Russian Automation Conference (RusAutoCon), Sochi, Russia.

[26] Huang, S., Guo, Y., Zha, S., Wang, F., \& Fang, W. (2017). A real-time location system based on RFID and UWB for digital production workshop. Procedia Cirp, 63, 132-137.

https://doi.org/10.1016/j.procir.2017.03.085

[27] Ding, B., Chen, L., Chen, D., \& Yuan, H. (2008). Application of RTLS in warehouse management based on RFID and Wi-Fi. 4th International Conference on Wireless Communications, Networking and Mobile Computing, Dalian, China.

[28] Simões, W. C., Machado, G. S., Sales, A., de Lucena, M.M., Jazdi, N., \& de Lucena, V.F. (2020). A Review of Technologies and Techniques for Indoor Navigation Systems for the Visually Impaired. Sensors, 20(14), 3935. https://doi.org/10.3390/s20143935

[29] Chon, H. D., Jun, S., Jung, H., \& An, S.W. (2004). Using RFID for accurate positioning. Journal of Global Positioning Systems, 3(1-2), 32-39.

[30] Dash, A. (2009). Lost+ found: making the right choice in equipment location systems. Health Facilities Management, 22(11), 19-21.

[31] Bayrakdar, M. E. (2019). Cost Efficient Sensor Node Placement Approach for Using Minimum Number of Node in Wireless Sensor Networks. Bilecik Şeyh Edebali University Journal of Science, 6, 59-73. (In Turkish)

\section{Figures}




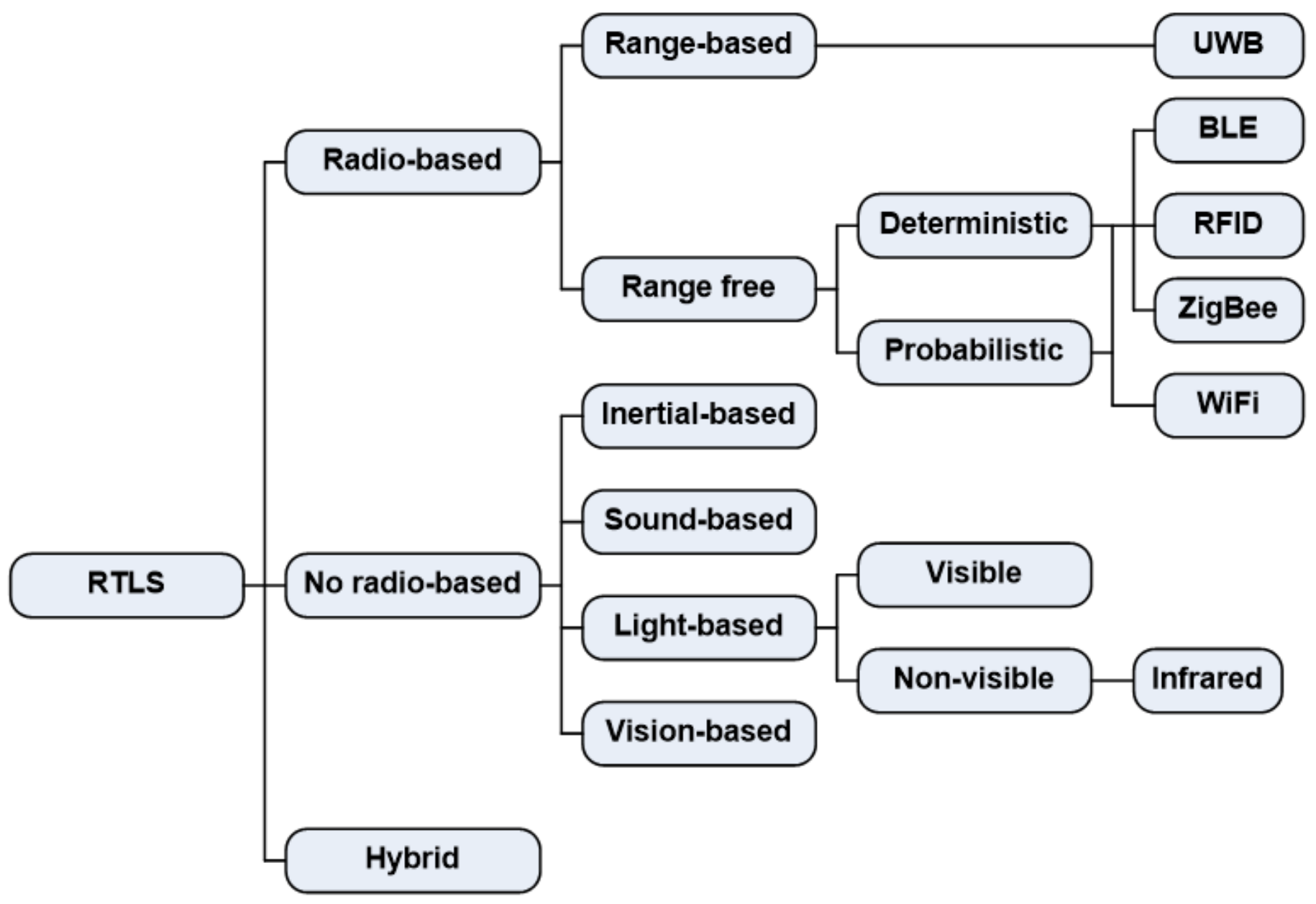

Figure 1

Classification of RTLSs 


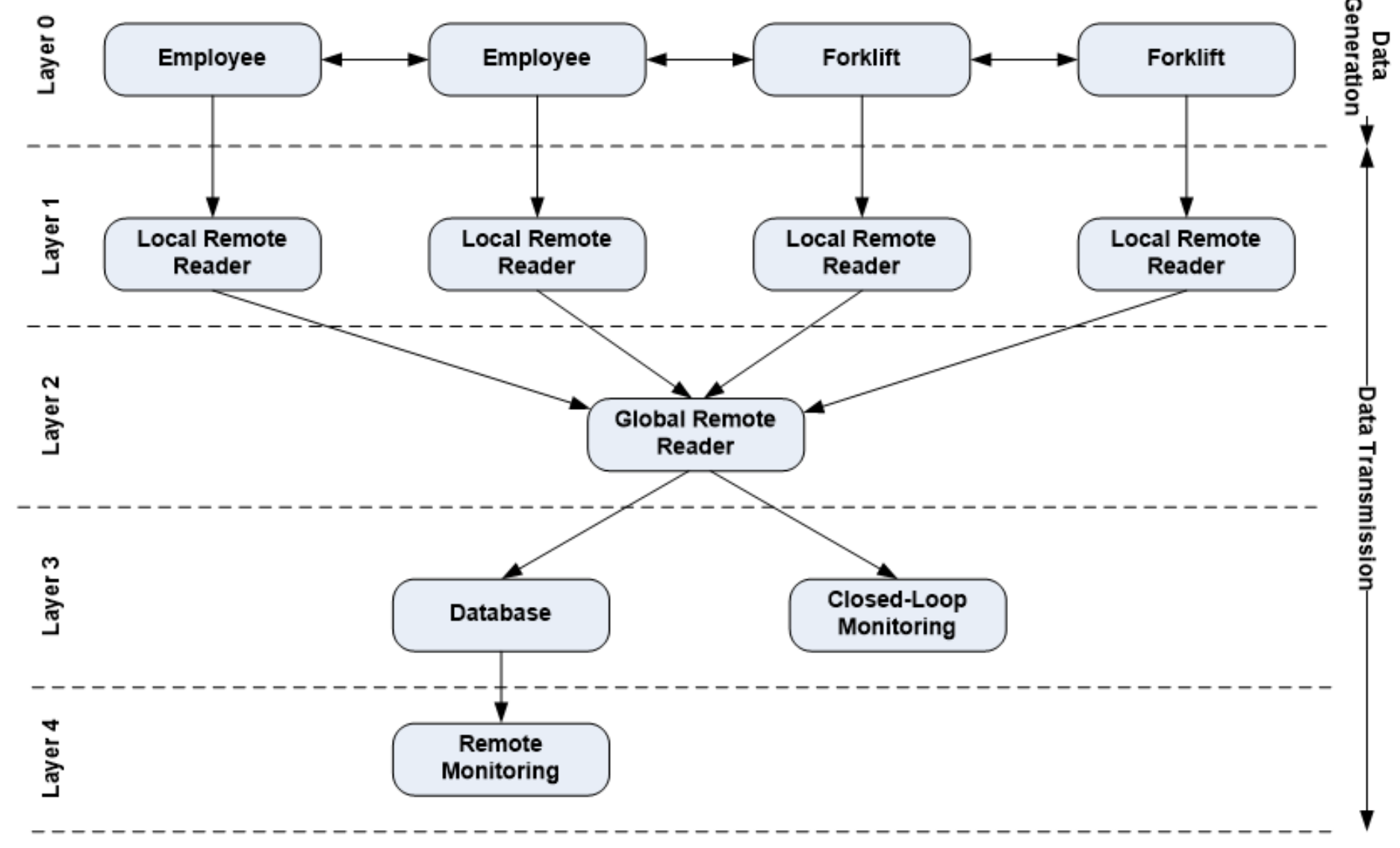

Figure 2

Data flow levels in the system

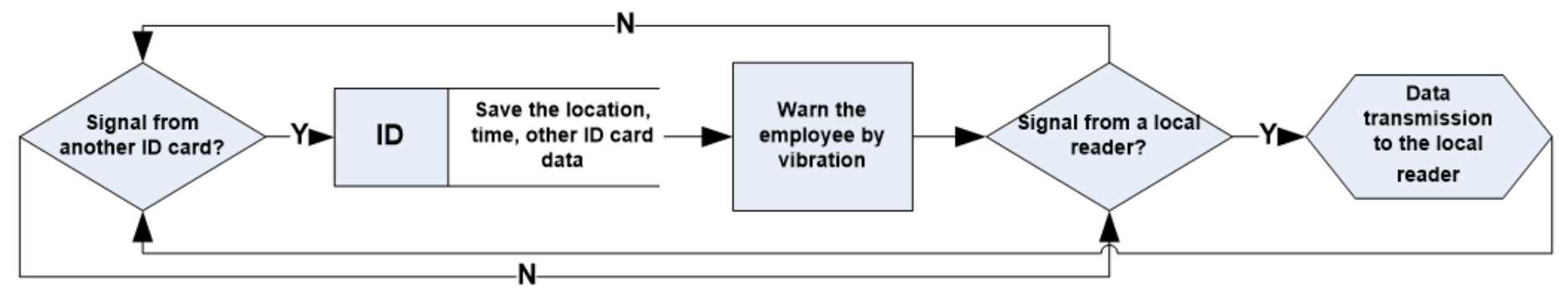

Figure 3

Data flow of the maintaining social distance 


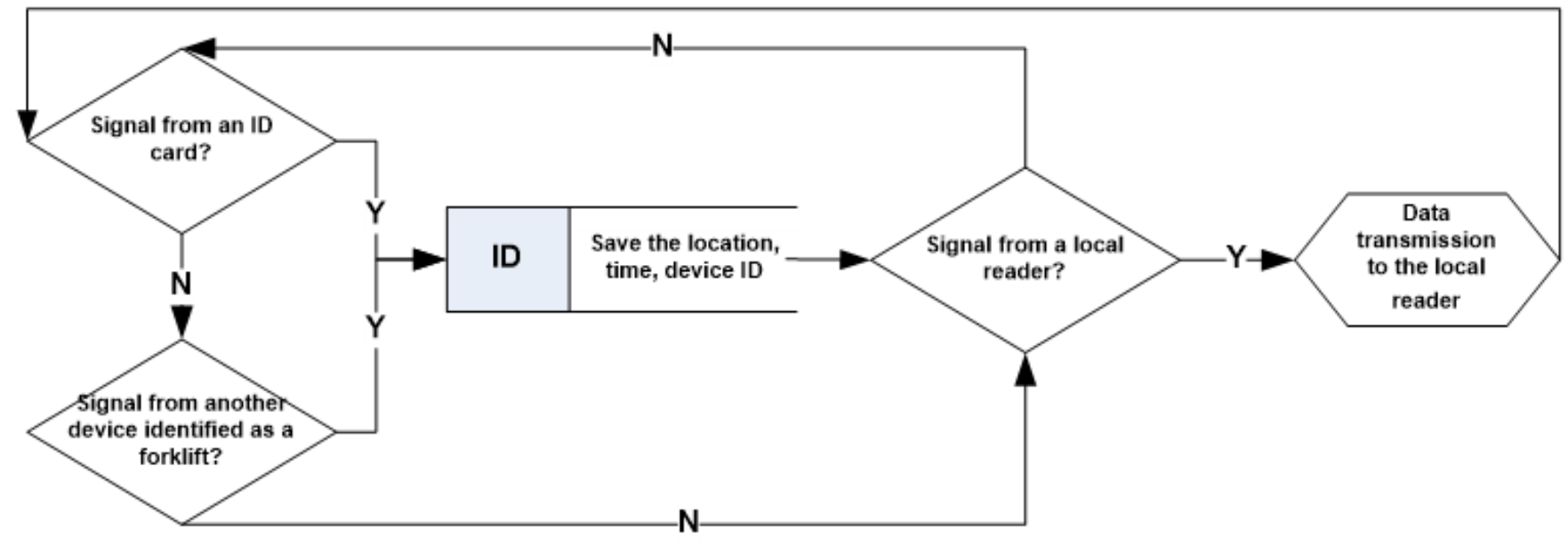

4a.

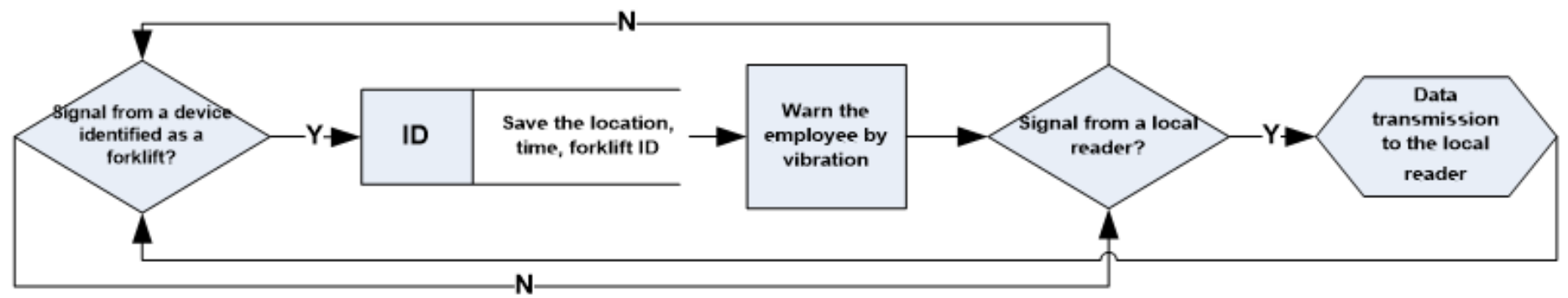

4b.

Figure 4

Data flow of the employee and forklift accident prevention system 


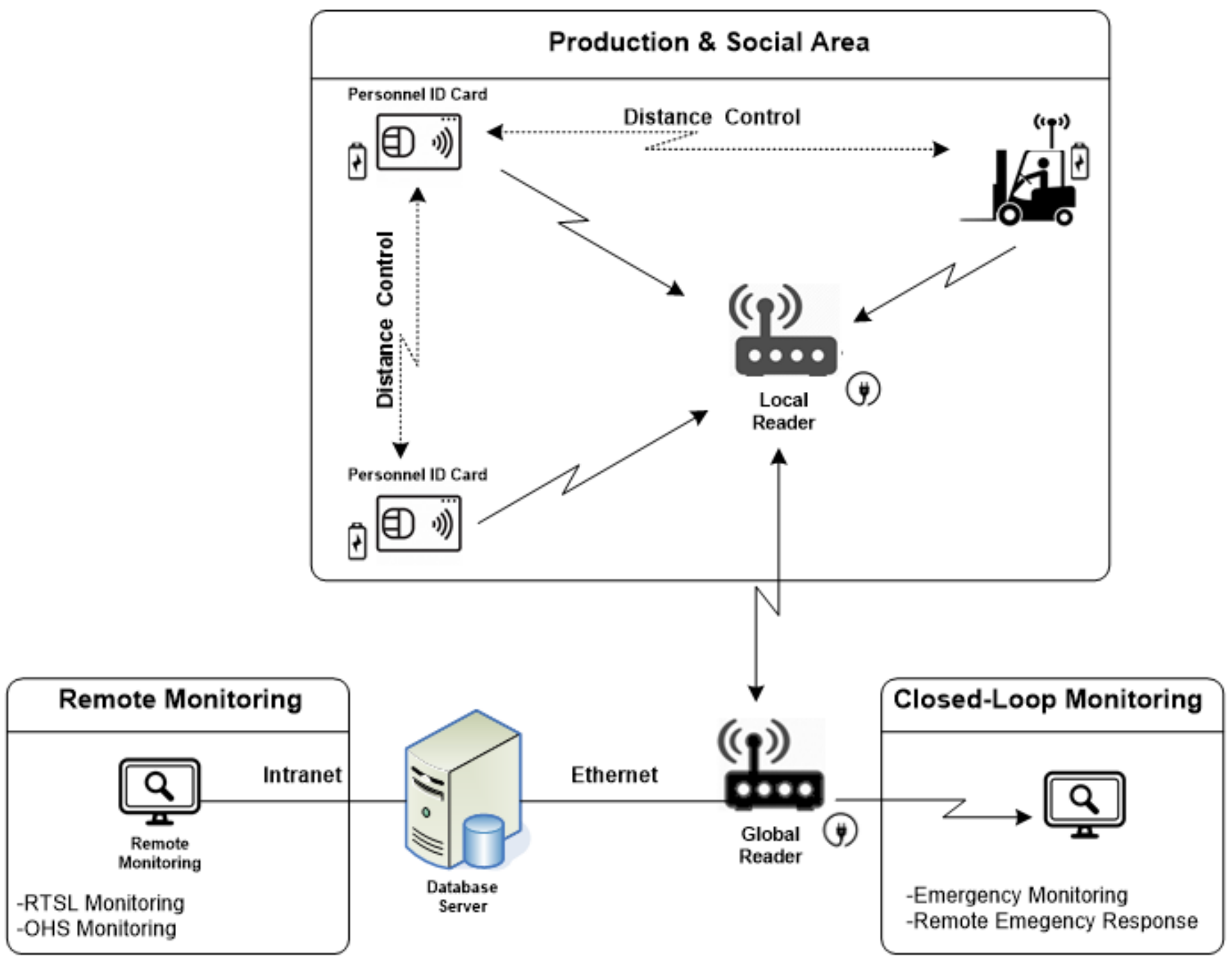

Figure 5

The system architecture of the proposed RTLS 


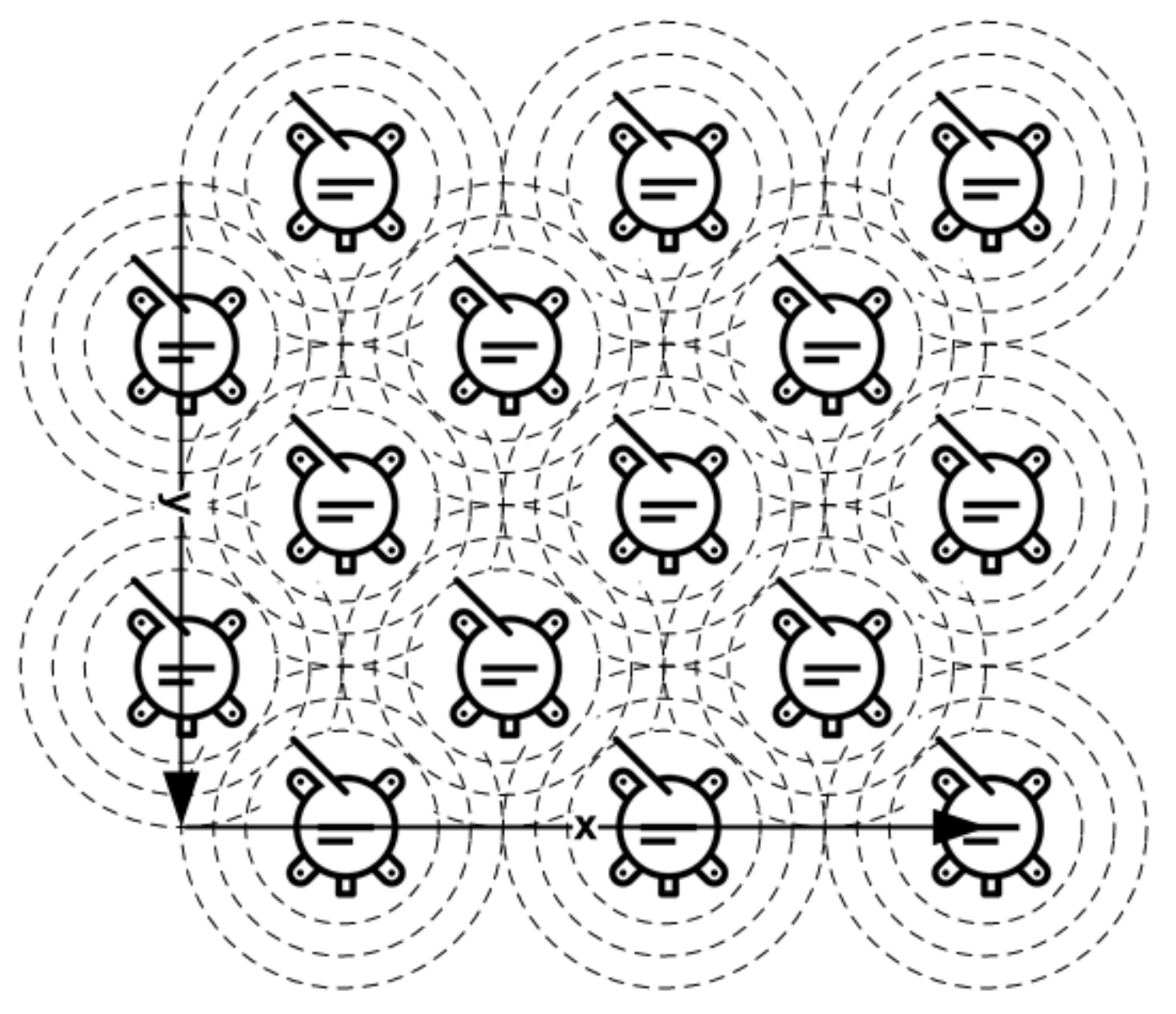

Figure 6

The system architecture of the proposed RTLS

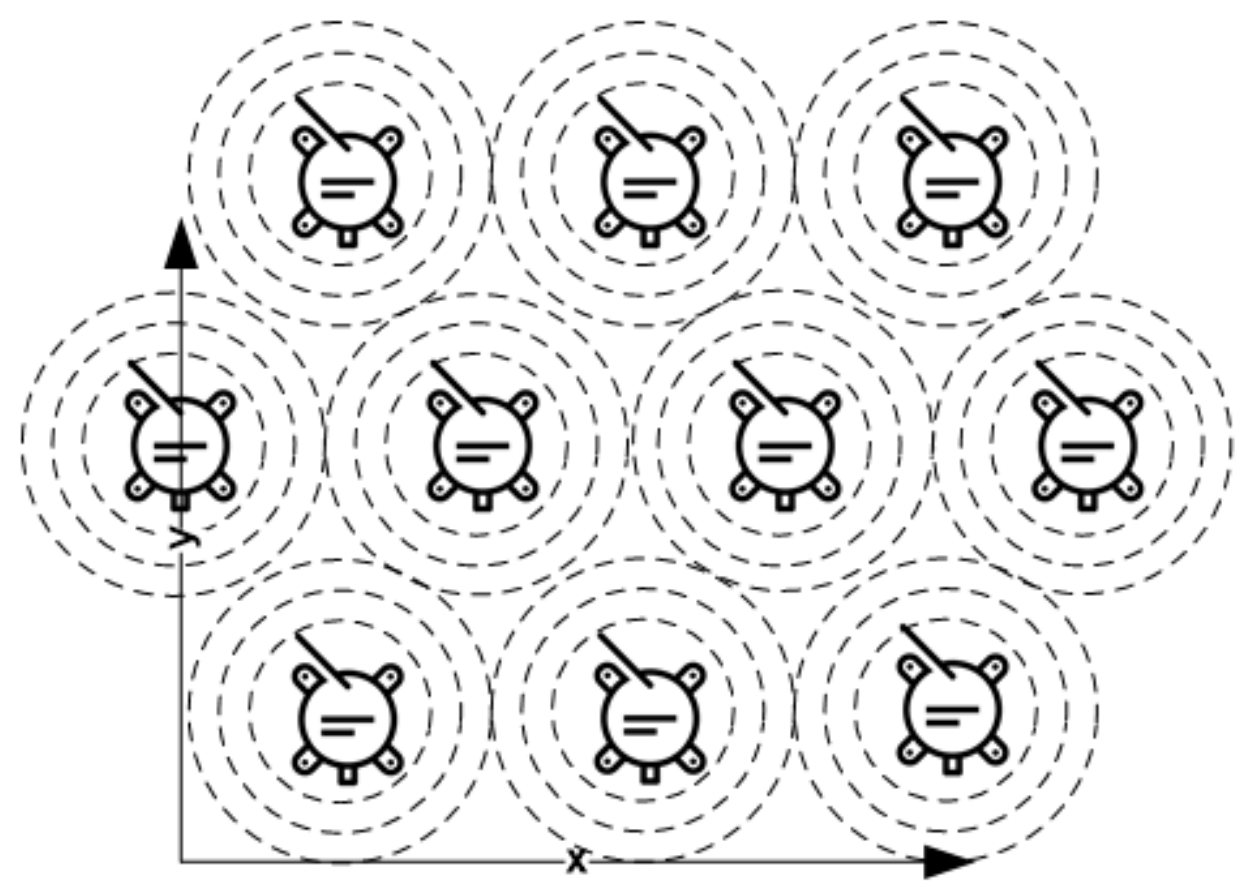


Figure 7

Placement of LRRs according to policy \#2
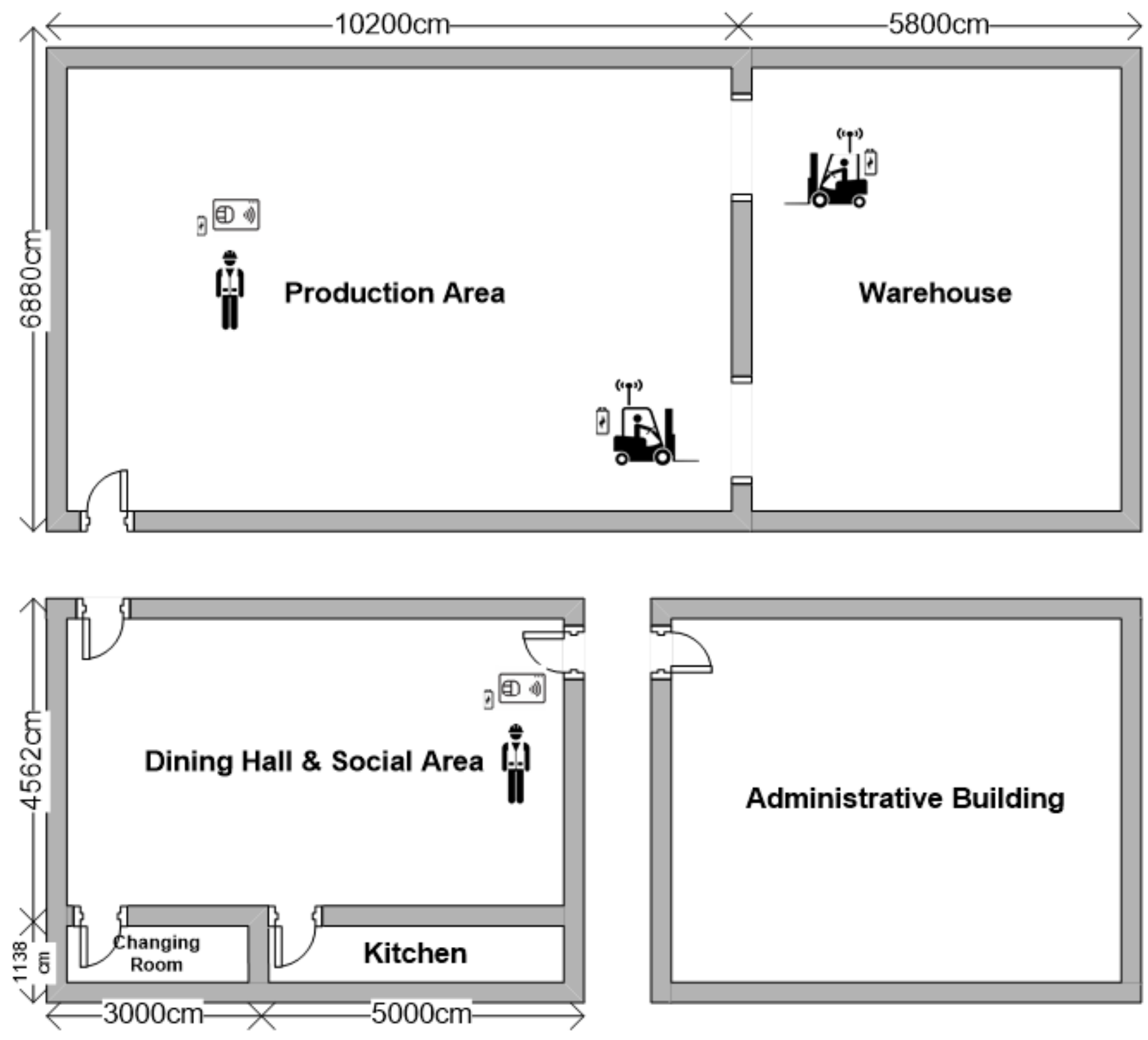

Figure 8

A representative production facility layout 